\title{
Groundwater Quality in the Middle Sacramento Valley, California
}

Groundwater provides more than $\mathbf{4 0}$ percent of California's drinking water. To protect this vital resource, the State of California created the Groundwater Ambient Monitoring and Assessment (GAMA) Program. The Priority Basin Project of the GAMA Program provides a comprehensive assessment of the State's groundwater quality and increases public access to groundwater-quality information. The Middle Sacramento Valley is one of the study units being evaluated.

\section{The Middle Sacramento Valley Study Unit}

The M iddle Sacramento Valley (M SA CV) study unit is located in California's Sacramento Valley. The 3,340-square-mile study unit includes eight groundwater subbasins: East Butte, N orth Yuba, South Yuba, Sutter, Vina, West B utte, Colusa, and Corning (California D epartment of Water Resources, 2003). In the M SA CV study unit, summers are hot and dry and winters are cool and moist. Average annual rainfall ranges from 17 to 32 inches. M ost rivers and streams flowing across the M SACV study unit drain into the Sacramento River.

A quifers in the study unit consist of discontinuous lenses of gravel, sand, silt, and clay, which primarily are derived from the Sierra N evada mountain range to the east and the Coast Ranges to the west. The primary aquifers in the M SA CV study unit are defined

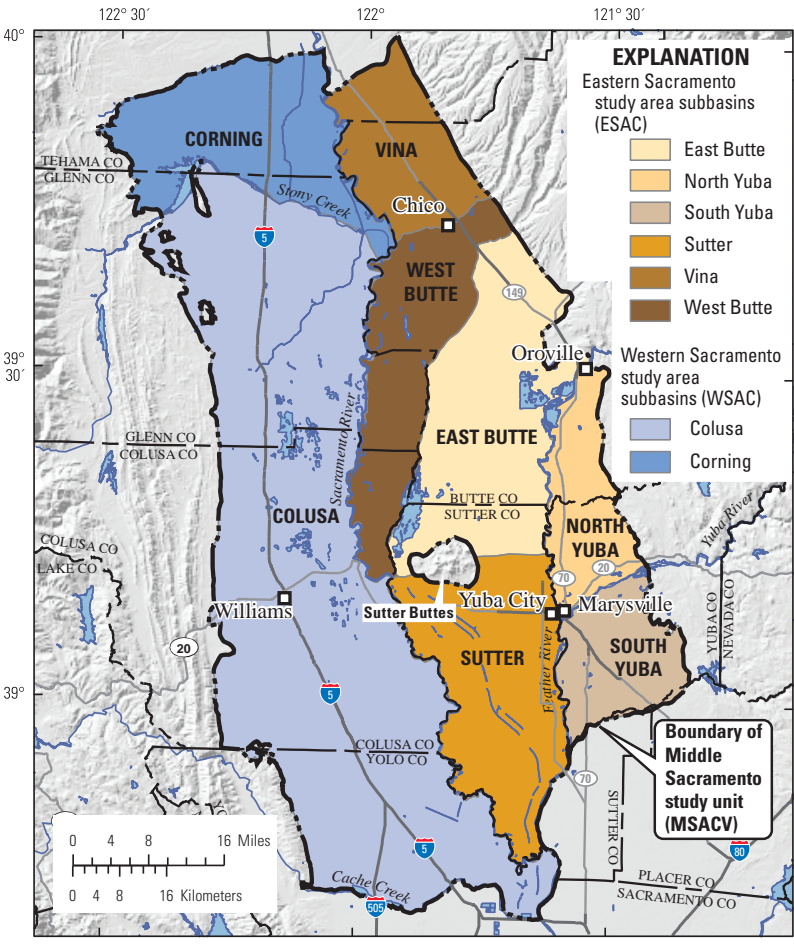
as those parts of the aquifers corresponding to the perforated intervals of wells listed in the California Department of Public Health (CDPH) database. The public-supply wells monitored by CDPH typically are completed within the primary aquifers to depths of 175- 375 feet below land surface (bls). The wells are constructed with solid casing from land surface to depths of about 100-200 feet bls, and are perforated below the solid casing to allow water into the well. Water quality in the primary aquifers may differ from water quality in the shallow or deep parts of the aquifer system.

L and use in the study unit is about 67 percent (\%) agricultural, 30\% natural (primarily grassland), and 3\% urban. The largest urban areas in the study unit are the cities of Chico and Yuba City.

Recharge to the groundwater flow system primarily is from rivers and streams draining the Sierra N evada and the Coast Ranges, and from infiltration of precipitation and applied surface water (California Department of Water R esources, 2003). The primary sources of groundwater discharge (water leaving the flow system) are from pumping for irrigation and municipal water supply, evaporation from areas with a shallow depth to water, and discharge to streams.

\section{Overview of Water Quality}

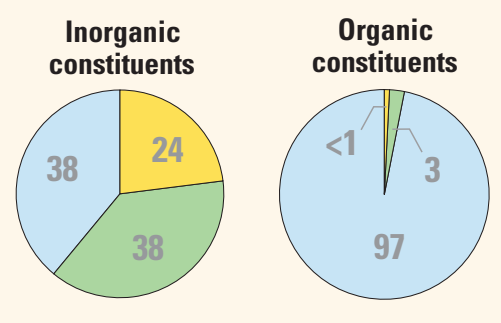

CONSTITUENT CONCENTRATIONS

$\bigcirc$ High $\bigcirc$ Moderate $\bigcirc$ Low or not detected

Values are a percentage of the area of the primary aquifers with concentrations in the three specified categories.

GA M A's Priority B asin Project eval uates the quality of untreated groundwater. However, for context, benchmarks established for drinking-water quality are used for comparison. B enchmarks, and definitions of high, moderate, and low concentrations, are discussed in the inset box, "B enchmarks for Evaluating Groundwater Quality" on page 3.

$M$ any inorganic constituents occur naturally in groundwater. The concentrations of the inorganic constituents can be affected by natural processes as well as by human activity. In the M SA CV study unit, one or more inorganic constituents were detected at high concentrations in about $24 \%$ of the primary aquifers and at moderate concentrations in about $38 \%$.

Organic constituents are present in products used in the home, business, industry, and agriculture. Organic constituents can enter the environment through normal usage, spills, or improper disposal. In the MSACV study unit, one or more organic constituents were detected at high concentrations in less than $(<) 1 \%$ of the primary aquifers, and at moderate concentrations in about 3\%. 


\section{RESULTS: Groundwater Quality in the Middle Sacramento Valley Study Unit}

\section{INORGANIC CONSTITUENTS}

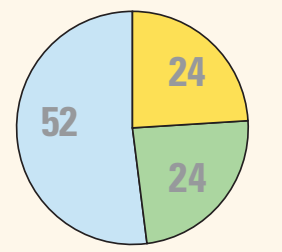

\section{Trace and minor elements}

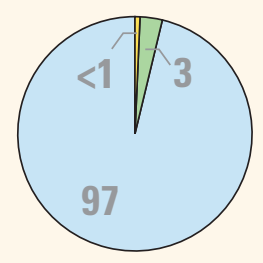

Radioactive constituents

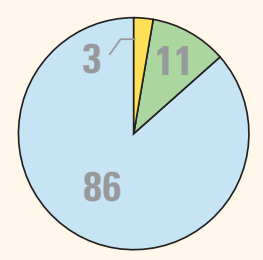

\section{Nutrients}
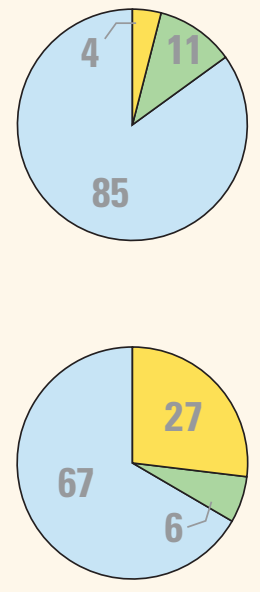

\section{Iron or manganese}

SPECIAL-INTEREST CONSTITUENTS

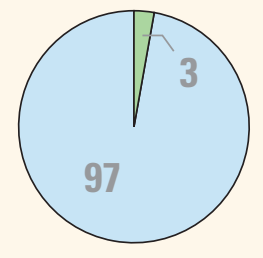

\section{Inorganic Constituents with Human-Health Benchmarks}

Trace and minor elements are naturally present in the minerals in rocks and soils, and in the water that comes into contact with those materials. In the M SACV study unit, one or more trace elements were detected at high concentrations in about $24 \%$ of the primary aquifers. A rsenic and boron were the two trace elements that were most frequently detected at concentrations greater than benchmarks (22 and $7 \%$ of the primary aquifers, respectively). Fluoride also was detected at high concentrations in $<1 \%$ of the primary aquifers.

Radioactivity is the release of energy or energetic particles during structural changes in the nucleus of an atom. M ost of the radioactivity in groundwater comes from decay of naturally occurring isotopes of uranium and thorium in minerals in the sediments of the aquifer. In the M SA CV study unit, concentrations of radioactive constituents were high in $<1 \%$ of the primary aquifers and at moderate concentrations in about $3 \%$.

N utrients, such as nitrate and nitrite, are naturally present at low concentrations in groundwater. High and moderate concentrations generally occur as a result of human activities, and can come from fertilizer applied to crops and landscaping, seepage from septic systems, and human and animal waste. In the M SA CV study unit, nutrients were detected at high concentrations in about $3 \%$ of the primary aquifers and at moderate concentrations in about $11 \%$ of the primary aquifers.

\section{Inorganic Constituents with Non-Health Benchmarks}

(Not included in water-quality overview charts shown on the front page)

Some constituents affect the aesthetic properties of water, such as taste, color, or odor, or may create nuisance problems, such as staining and scaling. The State of California has a recommended and an upper limit for total dissolved solids (TDS) in drinking water. In the M SA CV study unit, TDS concentrations were high (greater than the upper limit) in about $4 \%$ of the primary aquifers. Chloride concentrations, a component of TDSs, also were high in $2 \%$ of the primary aquifers. M oderate concentrations (between the recommended and upper limit) of TDS were detected in about $11 \%$ of the primary aquifers.

Iron and manganese are naturally occurring elements that often co-occur. I ron or manganese concentrations (or both) were present at high concentrations in about $27 \%$ of the primary aquifers and at moderate concentrations in about $6 \%$.

\section{Perchlorate}

(Not included in water-quality overview charts shown on the front page)

Perchlorate is an inorganic constituent that has been regulated in California drinking water since 2007. It is an ingredient in rocket fuel, fireworks, safety flares, and other products, may be present in some fertilizers, and al so occurs naturally at low concentrations in groundwater. In the MSACV study unit, perchlorate was not detected at high concentrations in the primary aquifers but was detected at moderate concentrations in about $3 \%$ of the primary aquifers. 


\section{RESULTS: Groundwater Quality in the Middle Sacramento Valley Study Unit}

\section{ORGANIC CONSTITUENTS}

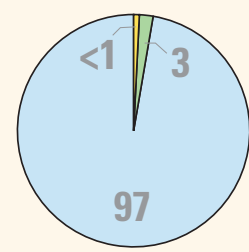

Solvents

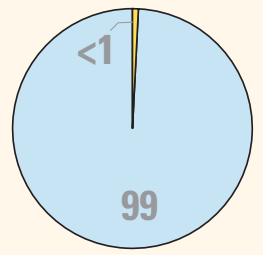

\section{Gasoline additives}

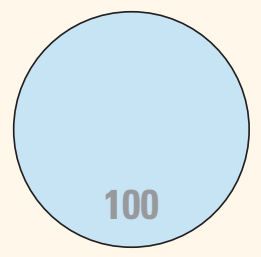

\section{Other VOCs}

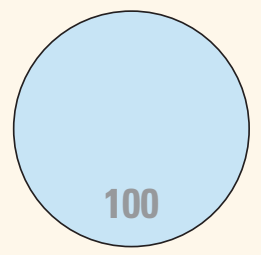

\section{Organic Constituents}

The Priority Basin Project uses laboratory methods that can detect the presence of volatile organic compounds ( $\mathrm{VOC}$ ) and pesticides at low concentrations, far below human-health benchmarks. VOCs and pesticides detected at these low concentrations can be used to trace the pathways of water from the landscape into the aquifer system.

\section{Volatile Organic Compounds with Human-Health Benchmarks}

VOCs are present in many household, commercial, industrial, and agricultural products, and are characterized by their tendency to volatilize into the air.

Solvents are used for a number of purposes, including manufacturing and cleaning. In the M SACV study unit, solvents were detected at high concentrations in $<1 \%$ of the primary aquifers, and at moderate concentrations in about $3 \%$ of the primary aquifers.

Gasoline additives are added to gasoline to make it burn more efficiently. Gasoline additives were detected at high concentrations in $<1 \%$ of the primary aquifers. The gasoline additive detected at high concentrations was benzene.

Other VOCs include trihal omethanes and organic synthesis reagents. Trihal omethanes can form during disinfection of water supplies and may enter groundwater by the infiltration of landscape irrigation water or leakage from water distribution lines. Organic synthesis reagents are used in the manufacture of complex organic molecules. In the M SA CV study unit, other V OC s (trihalomethanes and organic synthesis reagents) were not detected at high or moderate concentrations in the primary aquifers.

\section{Pesticides with Human-Health Benchmarks}

Pesticides are applied to crops, lawns, gardens, around buildings, and along roads to help control weeds, insects, fungi, and other pests. In the MSA CV study unit, pesticides were not detected at high or moderate concentrations in the primary aquifers.

\section{BENCHMARKS FOR EVALUATING GROUNDWATER QUALITY}

GA M A's Priority B asin Project uses benchmarks established for drinking water to provide context for evaluating the quality of untreated groundwater. A fter withdrawal, groundwater may be disinfected, filtered, mixed, and exposed to the atmosphere before being delivered to consumers. Federal and $\mathrm{C}$ alifornia regulatory benchmarks for protecting human health ( $M$ aximum Contaminant $L$ evel, $M C L$ ) are used for the evaluation when available. Otherwise, non-regulatory benchmarks for protecting aesthetic properties (Secondary M aximum Contaminant L evel, SM CL) such as taste and odor, and non-regulatory benchmarks for protecting human health (Notification L evel, NL, and L ifetime Health A dvisory, HAL), are used.

\section{High, moderate, and low concentrations are defined relative to benchmarks}

Concentrations are considered high if they are greater than a benchmark. For inorganic constituents, concentrations are moderate if they are greater than one-half of a benchmark. For organic and special-interest constituents, concentrations are moderate if they are greater than one-tenth of a benchmark; this lower threshold was used because organic constituents generally are less preval ent and have smaller concentrations relative to benchmarks than inorganic constituents. Low includes nondetections and values less than moderate concentrations. M ethods for evaluating water quality are discussed in B ennett and others (2010).

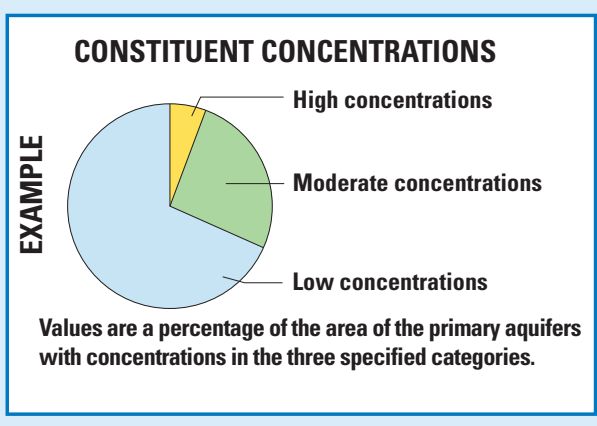




\section{Comparison of Arsenic Concentrations to Other Sacramento Valley Study Units}

A rsenic was detected at concentrations greater than the regulatory $M C L$ benchmark of 10 micrograms per liter in $22 \%$ of the primary aquifers in the M SA CV study unit, a higher proportion than what was observed in the Southern or N orthern Sacramento Valley study units. High concentrations of arsenic were found in wells located along the Sacramento and Feather Rivers, likely because geochemical conditions in the sediments favor arsenic solubility. Groundwater in the Quaternary alluvium al ong the Sacramento River and in the Delta commonly has low dissolved oxygen content (reducing conditions), and reducing conditions are correlated with el evated arsenic concentrations in Sacramento Valley groundwater (M ilby Dawson, 2001).

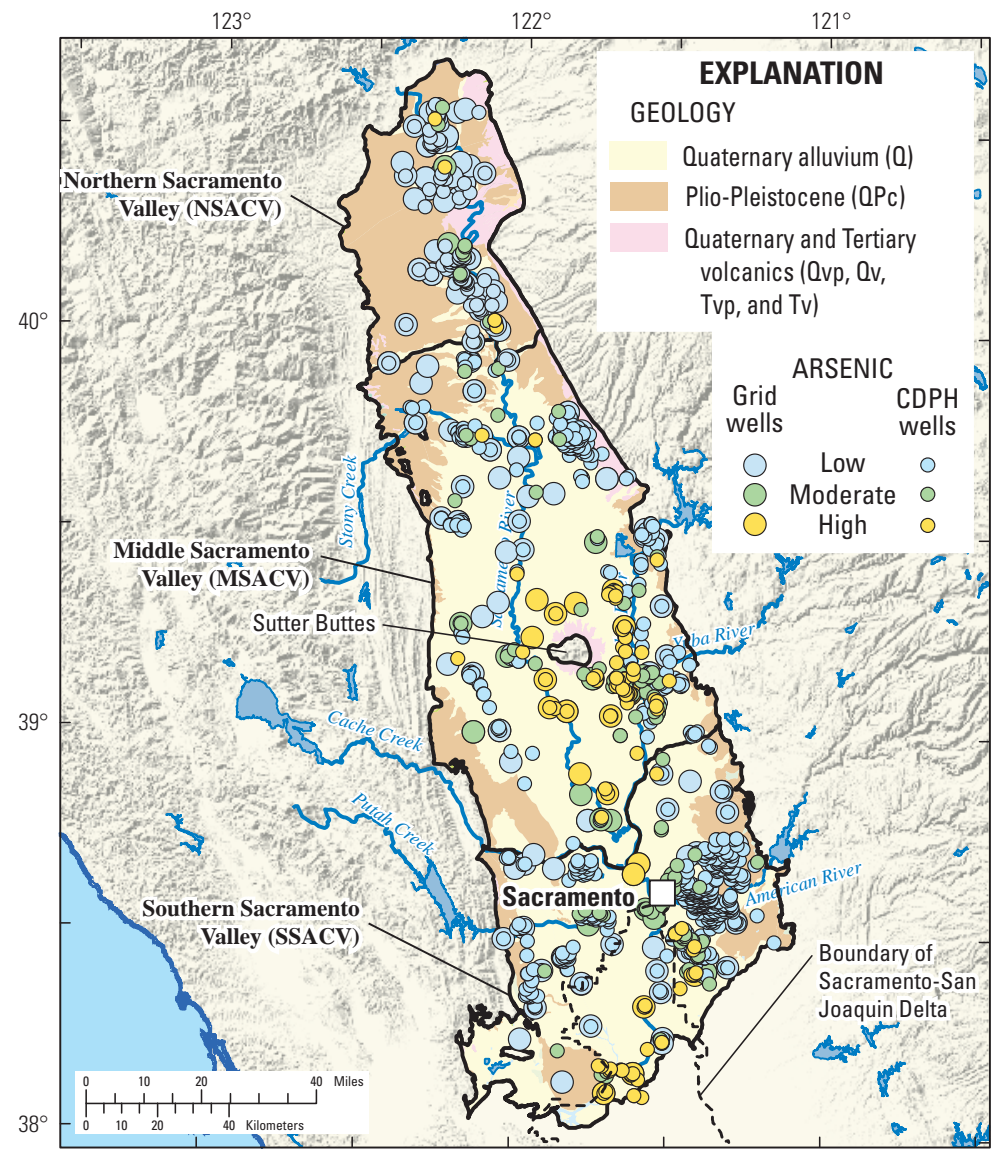

Northern Sacramento Valley study unit

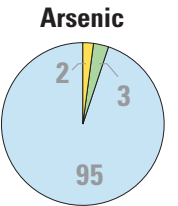

Middle Sacramento Valley study unit

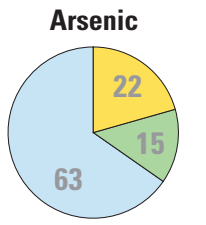

Southern Sacramento Valley study unit

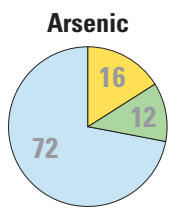

By George L. B ennett, V, M iranda S. Fram, and K enneth B elitz

\section{SELECTED REFERENCES}

Bennett, G.L., V, Fram, M .S., and B elitz, Kenneth, 2011, Status of groundwater quality in the Southern, M iddle, and N orthern Sacramento Valley study units, 2005-08-California GA M A Program Priority Basin Project: U.S. Geological Survey Scientific Investigations R eport 2011-5002, 120 p. (A Iso available at $h t t p: / / w w w . p u b s . u s g s . g o v / s i r / 2011 / 5002$.

California Department of Water Resources, 2003, California's groundwater: California Department of Water Resources B ulletin 118, 246 p., accessed October 26, 2010, at http://www.water.ca.gov/groundwater/bulletin118/update2003.cfm.

Dawson, B.J., 2001, G round-water quality in the Southeastern Sacramento Valley A quifer, California, 1996: U.S. Geological Survey Water-Resources Investigations Report 01-4125, 24 p. (A Iso available at http://pubs.usgs.gov/wri/wri014125.)

Schmitt, S.J ., Fram, M .S., Dawson, B.J ., and B elitz, K enneth, 2008, Ground-water quality data in the middle Sacramento Valley study unit, 2006- Results from the California GAM A program: U.S. Geological Survey Data Series 358, 100 p. (Also available at $h$ ttp://pubs.usgs.gov/ds/385.)
Priority Basin Assessments

GAM A's Priority B asin Project (PBP) assesses water quality in that part of the aquifer system used for drinking water, primarily public supply. Water quality in the primary aquifers may differ from water quality in shallower and deeper parts of the aquifers. GA M A's D omestic Well Project assesses water quality in the shallow parts of the aquifer system. Ongoing assessments are being conducted in more than 120 basins throughout California.

The PBP assessments are based on a comparison between constituent concentrations in untreated groundwater and drinking-water benchmarks established for protection of human heal th and for aesthetic concerns. The PBP does not evaluate the quality of drinking water delivered to consumers.

The PBP uses two scientific approaches for assessing groundwater qual ity. The first approach uses a network of wells to statistically assess the status of groundwater quality. The second approach combines water-quality, hydrologic, geographic, and other data to assess the factors that affect water quality. In the M SA CV study unit, data were collected by the PBP in 2006 and from the CDPH database for 2003-2006. The PBP includes chemical analyses generally not available as part of regulatory compliance monitoring, including measurements at concentrations much lower than human-health benchmarks and measurement of constituents that can be used to trace the sources and movement of groundwater.

\section{For more information}

Technical reports and hydrologic data collected for the GA M A Program may be obtained from:

GAMA Project Chief

U.S. Geological Survey California Water Science Center 4165 Spruance R oad, Suite 200

San Diego, CA 92101

Telephone number: (619) 225-6100

WEB: http://ca.water.usgs.gov/gama

GAMA Program Unit

State Water Resources Control Board Division of Water Quality

PO B ox 2231, Sacramento, CA 95812

Telephone number: (916) 341-5779

WEB: http://www.waterboards.ca.gov/ water_issues/programs/gama 